NBER WORKING PAPER SERIES

THE VALUE OF LIFE NEAR ITS END AND TERMINAL CARE

\author{
Gary Becker \\ Kevin Murphy \\ Tomas Philipson \\ Working Paper 13333 \\ http://www.nber.org/papers/w13333
}

\author{
NATIONAL BUREAU OF ECONOMIC RESEARCH \\ 1050 Massachusetts Avenue \\ Cambridge, MA 02138
}

August 2007

We are thankful for comments from Dana Goldman, Anupam Jena, Darius Lakdawalla, and Eric Sun as well as seminar participants at The University of Chicago, Washington University, The 2007 IHEA Meetings in Copenhagen, and RAND. Financial support from National Institutes of Aging (Grant P30 AG 12857) as well as Amgen is gratefully acknowledged. The views expressed herein are those of the author(s) and do not necessarily reflect the views of the National Bureau of Economic Research.

(C) 2007 by Gary Becker, Kevin Murphy, and Tomas Philipson. All rights reserved. Short sections of text, not to exceed two paragraphs, may be quoted without explicit permission provided that full credit, including $\odot$ notice, is given to the source. 
The Value of Life Near its End and Terminal Care

Gary Becker, Kevin Murphy, and Tomas Philipson

NBER Working Paper No. 13333

August 2007

JEL No. I1,I11,I18,I32,I39,J0

\begin{abstract}
$\underline{\text { ABSTRACT }}$
Medical care at the end of life, which is often is estimated to contribute up to a quarter of US health care spending, often encounters skepticism from payers and policy makers who question its high cost and often minimal health benefits. It seems generally agreed upon that medical resources are being wasted on excessive care for end-of-life treatments that often only prolong minimally an already frail life. However, though many observers have claimed that such spending is often irrational and wasteful, little explicit and systematic analysis exists on the incentives that determine end of life health care spending. There exists no positive theory that attempts to explain the high degree of end-of life spending and why differences across individuals, populations, or time occur in such spending. This paper attempts to provide the first rational and systematic analysis of the incentives behind end of life care. The main argument we make is that existing estimates of the value of a life year do not apply to the valuation of life at the end of life. We stress the low opportunity cost of medical spending near ones death, the importance of keeping hope alive in a terminal care setting, the larger social value of a life than estimated in private demand settings, as well as the insignificance in quality of life in lowering its value. We derive how an ex-ante perspective in terms of insurance and $R \& D$ alters some of these conclusions.
\end{abstract}

Gary Becker

Department of Economics

The University of Chicago

1126 East 59th Street

Chicago, IL 60637

gbecker@uchicago.edu

Kevin Murphy

Graduate School of Business

The University of Chicago

5807 S. Woodlawn Ave.

Chicago, IL 60637

and NBER

kevin.murphy@gsb.uchicago.edu
Tomas Philipson

Irving B. Harris Graduate School

of Public Policy Studies

The University of Chicago

1155 E 60th Street

Chicago, IL 60637

and NBER

t-philipson@uchicago.edu 


\section{Section 1: Introduction}

Medical care at the end of life often encounters skepticism from payers and policy makers who question its high cost and often minimal health benefits. Indeed, many studies have found that a large share of overall life-time spending on medical care, about a quarter, occurs at an individual's last year of life, regardless of whether that care is privately or publicly financed (Hogan et al. 2000; Lubitz and Riley 1993). It therefore seems generally agreed upon that medical resources are being wasted on excessive care for end-of-life treatments that often only prolong minimally an already frail life. This excessive care at the end of life partially affects the overall distribution of the spending on health care as it is highly skewed, and the average spending level is driven by the few biggest spenders. This is often driven by extreme spending levels on dying individuals. For example, it has estimated that about close to half of the overall spending on old individuals in the US stems from the top $5 \%$ of the spending distribution (Garber et al (1998)).

From an economic standpoint, it seems obvious that much of this extreme end of lifespending is irrational in the sense that the value of a life year is often estimated to be in the range of 100 thousand dollars ${ }^{2}$, but overall spending in extending life a few months near death can sometimes be in the millions. Indeed, it can be argued that this vast misallocation of resources induced by excessive end of life health care has important consequences for the overall economy as end of life care makes up a substantial share of the $16 \%$ or so of the economy spent on health care. This over-spending on terminal care also has important implications for the public programs, such as Medicare and Medicaid in the US, that pay for much of this excessive end of life care, as well as Social Security, which ends up financing the longer, but less attractive, living it induces.

However, though many observers have claimed that such spending is often futile, irrational, and wasteful, little explicit and systematic analysis exists on the incentives that determine end of life health care spending. More importantly, no positive theory exists that attempt to explain the high degree of end-of life spending and why differences across individuals, populations, or time occur in such spending. We argue that such a positive analysis is the prerequisite before any normative claims can be made and before any policy proposals aimed at limiting such care can be justified on an efficiency basis.

In this paper, we attempt to provide the first rational and systematic analysis of the incentives behind end of life care. The main argument we make is that existing estimates of the value of a life year do not apply to the valuation of life at the end of life. The main issue is that existing estimates of the value of a life year, e.g. from labor market studies,

\footnotetext{
${ }^{2}$ It is interesting to note that this estimate of the value of a life year is in the range of a simple valuation of the time of a year in the US using wages as the lower bound on the value of leisure time. More precisely, if average labor earnings are in the range of \$30-40 thousand per year and working time makes up about a third of total time awake (8 hour work day during weekdays and 7 hours of daily sleep) then the range for a lower bound on the value of a life year is $\$ 90-120$ thousand. Also, see Hirth et al (2000) for a survey indicating larger values.
} 
product demand studies, or regulatory studies, are inapplicable to the valuation that takes place near end of life. In particular, several forces operate in allocating resources towards extending life at its end that implies that the value of extending life in those situations appear larger than those estimated in the existing literature.

First, if resources have no value when dead, a self-interested individual would be willing to forego his entire wealth to extend his life when dying, even if the extension was minimal, only involving a few months. A substantial amount of spending on futile care is rational when there is no value of leaving wealth behind. This claim is highly related to existing evidence suggesting that more than half of personal bankruptcies are associated with unforeseen health care spending (Himmelstein (2005)). We stress that end of life care often involves infra-marginal valuation, rather than the marginal valuations estimated in the literature. When there is non-linearity in the willingness to pay, as when one values an additional year more on the margin the less of life one has left, then the infra-marginal tradeoff relevant for end-of life care differs from aggregating the marginal valuations estimated in the empirical literature. Indeed, many times when the concept of the value of a statistical life is taught and explained, it is prefaced with claiming that it is not about how much people are willing to pay to avoid the infra-marginal choice of having a gun put to their head, which is presumably ones wealth if self-interested. However, terminal care decisions are often of exactly that nature and the non-linearity therefore matters.

Second, we argue that an important ignored component of spending on end-of-life care concerns preserving "hope" of living, and that preserving hope raises valuation. We define the value of hope explicitly as the current consumption of future survival. If a patient is given 6 months to live, he values those 6 months less than if he knew he would live after that. The fear of knowing that the end is near is a bad. We derive how this value of hope raises the willingness to pay for what appears as otherwise futile treatments. This is because increased survival in the future is now "double-counted" as both having a current consumption value in addition to its traditional future consumption value. Related to such a value of hope would be in the option value of seeing a new treatment being discovered before ones death. Those diagnosed with HIV in the early 1990s clearly benefited from this optional value, taking advantage of the breakthrough treatments that came on the market in 1996. Indeed, the late Christopher Reed devoted much time and resources of the last part of his life finding a cure to save himself.

Third, the social value of a life is often greater than the private value of the same life. However, existing estimates of the value of a life year concerns only private valuation ${ }^{3}$. If the extension of a given persons life has positive external effects on others (family members, altruistic tax-payers, or interest groups benefiting from public provision of care), larger spending than what is privately optimal, and estimated, would be observed. Indeed, as the willingness to pay for life extension is limited privately by ones wealth, the mere existence of the Medicaid program for the poor in the US seems inconsistent with a

\footnotetext{
${ }^{3}$ See Becker, Philipson,, and Soares (2003) who discusses the general R\&D implications of a wedge in the social and private value of health care.
} 
private valuation approach being relevant, as it would be infeasible for those patients to pay the end of life care they receive.

Fourth, we argue that rational terminal care often is larger for frail patients than commonly argued. In particular, we show when the value of life-extension is the same regardless of the "quality" of life of the patient whose life is extended. Therefore, even though a person may be frail and in very ill health, it may nevertheless be rational for him to value life-extension as much as a perfectly healthy person. There is a vast health economic literature arguing that there is less value in prolonging a life of lower quality, as is the driving assumption of so called "quality-of-life-year" (QUALY) analysis. However, we argue that rational terminal care may often involves spending equally much for extending the life of a very frail person as it does for a perfectly healthy one. These forces stress the unrecognized benefits of terminal care spending conditional upon a disease occurring.

In addition, the paper extends the analysis of the benefits of terminal care spending to the value of terminal care insurance, in other words, the value of deciding how much wealth to allocate towards a potential future circumstance involving expensive terminal care. In addition, we consider the implications for $\mathrm{R} \& \mathrm{D}$ spending on terminal care when there is, as appears particularly relevant to terminal care, a strong desire to not limit care for dying patients. Lastly, we conclude by discussing how recent evidence may support our claims as well as the normative implications for public technology adoption our analysis implies. In summary, our analysis differs from previous analysis by attempting to understand the high, indeed often extreme, spending levels we observe for terminal care and explaining why such spending levels are often order of magnitudes higher than existing empirical estimates of the value of a life.

The paper may be briefly outlined as follows. Section 2 discusses the non-linearity of the value of life. Section 3 discusses how the value of hope raises spending. Section 4 discusses altruism within and across families affects terminal care. Section 5 discusses the impact of quality of life on rational terminal care. Section 6 discusses terminal care insurance and Section 7 R\&D for new terminal care technologies. Lastly, section 8 concludes.

\section{Section 2: Rational Terminal Care and the Non-Linearity of The Value of Life}

Consider the indirect utility function $V(Y, S)$ of an individual with lifetime wealth $\mathrm{Y}$ and survival function $S$. For example, this indirect utility function may be the one resulting from a canonical consumption problem of the type

$$
V(Y, S)=\max \int_{0}^{\infty} \exp (-\rho t) S(t) u(c(t)) d t
$$

subject to 


$$
Y=\int_{0}^{\infty} \exp (-r t) S(t) y(t) d t=\int_{0}^{\infty} \exp (-r t) S(t) c(t) d t,
$$

where $y(t)$ is income at age $t, c(t)$ consumption at $t, r$ and $\rho$ is the interest rate and timepreference.

For any such indirect utility function V, consider how much an individual would be willing to pay for a product that changed his survival function from $S$ to $S$ '. If we denote this amount by $\mathrm{v}\left(\mathrm{S}^{\prime}, \mathrm{S}\right)$, it satisfies ${ }^{4}$ :

$$
V\left(Y-v\left(S^{\prime}, S\right), S^{\prime}\right)=V(Y, S)
$$

This infra-marginal valuation formula ${ }^{5}$ differs from the existing value-of-life methodology used in the empirical literature which considers marginal changes in lifegains. This basic definition has remarkably strong implications for the economic value of raising survival for people who are near their end of their life. In particular, consider the value of a gain in survival to $S^{\prime}$ for an individual who is near his end of life, approximated by his existing survival function satisfying $S=0$. The value of this survival gain satisfies:

$$
v\left(S^{\prime}, 0\right)=Y \text { for all } S^{\prime}
$$

This extreme implication states that an individual is willing to pay his entire wealth for any gain in survival. In particular, the individual is willing to give up all his wealth no matter how small the gain in survival is. Put differently, if the opportunity cost of spending is zero when there is no value of leaving resources behind when dead, an individual is willing to spend all of his wealth to prolong life, though perhaps just briefly. This is an extreme implication induced by the complementarity between consumption and longevity (see Dow et al (1999)); as consumption is worthless without life, all of it will be sacrificed to gain more life.

More generally, there may be inherent non-linearity in the valuation of life in the sense that the marginal valuation of an additional life year differs with the level of survival. This implies that the value of big changes in survival cannot be as easily inferred from the value of small changes in survival. There is an implicit linearity assumption when aggregating up the value of life-improvements from the marginal valuations estimated in the existing literature. Consider the common practice of infra-marginal valuation through multiplying life years gained with a constant marginal value of a life year of, say, \$100 thousand. This will give a biased value of the infra-marginal value when the marginal value of life differs across levels of survival. To illustrate, consider the canonical

\footnotetext{
${ }^{4}$ An analogous argument occurs if the individual is asked to value a probability distribution over a set of feasible survival functions induced by treatment.

${ }^{5}$ See Becker et al (2005) for a more elaborate discussion of infra-marginal valuation in a different context.
} 
consumption problem above in the case of no discounting and a deterministic lifetime. In this case, the indirect utility function is made of $\mathrm{T}$ years of consumption of the overall wealth Y split up over the T years as in

$$
V(Y, T)=T u(Y / T)
$$

This implies the marginal value of life

$$
-V_{t} / V_{y}=Y / T-u / u^{\prime}
$$

If the second term does not dominate the first, the value of life will fall with length of life so that the more life one has the less one values an additional unit, similar to diminishing marginal utility in consuming other goods. For example, when the utility function takes the constant elasticity form, $u(c)=c^{a}$, then the indirect utility function takes the CobbDouglas form $V(Y, T)=T^{1-a} Y^{a}$ which displays the traditional declining marginal rate of substitution with the levels of the two goods. The important point is that if the marginal value of life declines with life in this way, empirical estimates of the marginal value of life from those who have a lot of it, e.g. workers healthy enough to participate in labor markets, may not reflect the value of terminal care for those who have less of it.

\section{Section 3: The Value of Hope in Terminal Care}

Many observers of end of life care claim that some notion of "hope" is important for patients to invest time and money into staying alive ${ }^{6}$. We formalize the value of hope as stemming from the current consumption of future survival; the person values knowing today that there is chance of living tomorrow. If certain death was known to prevail tomorrow the person would be without hope and thereby enjoy living less today. This is incorporated into the previous analysis by letting current utility become an increasing function of survival. Consider the case when this takes the linear form

$$
U(S, c)=H u(S)+U(c)
$$

Here, the parameter $H$ is the marginal value of hope and $u(S)$ is the current utility of future survival which rises in first-degree dominance. For example, $u(s)=\int S(t) d t$ may be the life-expectancy induced by the survival function. For the canonical consumption problem above the present value of expected utility now satisfies

$$
V(Y, S ; H)=A H u(s)+V(S, Y)
$$

\footnotetext{
${ }^{6}$ See Rasiel et al (2005) for a prospect-theory interpretation of terminal care with highly uncertain outcomes.
} 
where $A$ is the value of a life-long annuity and $V(Y, S)$ is the value function without hope from before. If we denote by $v(H)$ the infra-marginal value of life as a function of the value of hope this satisfies

$$
V\left(Y-v(H), S^{\prime}\right)-V(Y, S)=H\left[A u(S)-A^{\prime} u\left(S^{\prime}\right)\right]
$$

The left hand side is simply the implicit definition of the standard infra-marginal value of life. The right hand side falls with the value of hope and the infra-marginal change in survival. Consequently the value of life as a function of hope, $v(H)$, is an increasing function. Whenever future survival is valued in terms of current consumption then future survival gains are 'double counted' in their value; they affect the value of future consumption in a standard manner but in addition also raises the value of current consumption. This double counting due to hope may take place more so in end of life care decisions than in the labor- or product market setting where marginal valuations of life are estimated.

We argued before that a declining marginal value of life with the level of longevity implied that empirical estimates of the value of life for healthy people would differ from the valuation relevant to terminal care. The analog argument can be made for a declining marginal value of hope with longevity. If the marginal value today of living in the future goes down with future longevity, then empirical estimates of the value of life are biased when applied to terminal care for two reasons; the first because the traditional value of life declines with longevity and the second that the value of hope does too.

\section{2: Hope and the Option Value of $R \& D$}

Future survival may not have consumption value in itself but may be valued in nonstandard ways through its effect on being able to take advantage of future technologies. In other words, there is an option value in taking advantage of current R\&D.

Consider when the time of arrival $A$ of a new discovery that cures the individual is distributed to arrive in the future according to the survival distribution $W(a)$ specifying the probability that the cure has not arrived by time a given time; $A>a$. If the new survival purchased is S' then the probability of dying before arrival of the cure, so that total life span $T$ is less than or equal to $A$, is

$$
P(T \leq A)=\sum\left[S^{\prime}(T)-S^{\prime}(T-1)\right] W(t)
$$

In this case, the life-expectancy is just what it was before, $E\left[S^{\prime}\right]$. However, with probability $(1-P)$, the person lives to see the cure in which case the new survival-function is a function of the distribution of arrival times of the cure and the survival when on the new treatment denoted $S^{*}$. As this survival is higher than without a cure, $S^{*}>S^{\prime}$, the new overall survival is larger as well

$$
P S^{\prime}+(1-P) S^{*} \geq S^{\prime}
$$


The important point is that simply valuing the survival $S^{\prime}$ in itself under-values the gain in longevity, as this survival may lead to an additional life-extension conditional upon the arrival of a treatment during ones extended life. This option value of survival is likely to be the strongest for the more prevalent diseases when market size determines the amount of R\&D into cures, and hence the speed $W$ at which improvements in care arrive.

\section{Section 3: The Social vs Private Value of Life}

The previous section considered a self-interested individual in isolation, which is the concern of existing empirical work on the statistical value of a life through labor-, product-, or regulatory studies. This section considers the difference between the socialand private value of a life, when there is altruism within and across families.

\subsection{Altruism within Families}

Altruism within families operates in two ways in affecting the social value of a life. First, altruism towards children means that the value of life is reduced by bequest motives as the person dying values resources left behind. Second, altruism from children raises the value of life since people other than the dying patient value his survival.

More precisely, consider when a parent is terminally ill but now both the parent and the child share the payment that is undertaken to have the parent face survival $S$ ' rather than death $S=0$. Let the infra-marginal value of the parents life $v$ be split between the parent and the child according to the shares $(s, 1-s)$. Let $V^{p}\left(Y^{p}, S\right)$ and $V^{C}\left(Y^{C}\right)$ be the indirect utility functions of the parent and child, with the latter ignoring the child's survival prospects which are assumed to remain constant . The infra-marginal value $v$ of the parent's life is then defined by

$$
\left(1+a^{c}\right) V^{p}\left(Y^{p}-s v, S^{\prime}\right)+\left(1+a^{p}\right) V^{c}\left(Y^{c}-(1-s) v\right)=\left(1+a^{p}\right) V^{c}\left(Y^{p}+Y^{c}\right)
$$

where $a^{c}$ is the altruism of the child towards the parent and $a^{p}$ the altruism of the parent towards the child. The right hand side is the child's welfare when no treatment is undertaken for the parent, the parent dies, and all the wealth of the parent is left as bequest. The left hand side is the joint welfare of the two when the new life, and its payments, is shared. This may be rewritten as

$$
\left(1+a^{c}\right) V^{p}\left(Y^{p}-s v, S^{\prime}\right)=\left(1+a^{p}\right)\left[V^{c}\left(Y^{p}+Y^{c}\right)-V^{c}\left(Y^{c}-(1-s) v\right)\right]
$$

This simply equates the gain in welfare of the parent surviving with the foregone consumption of the child. Clearly, for large enough altruism of the child and low enough altruism of the parent, we may have that altruism raises the willingness to pay above the self-interested level of the parents wealth

$$
v>Y^{p}
$$


and for low enough altruism if the child and high enough altruism of the parent, it lowers the willingness to pay beyond the self-interested level

$$
v<Y^{p}
$$

If altruistic spending rise with income, the two side nature of altruism may therefore even raise spending above wealth levels of the sick individuals if the children are richer than the dying parent. Reversely, terminal care for children financed by their parents is likely to be far greater than the self-interested level of the wealth level of the child.

\subsection{Altruism across Families and Public Pay-As-You-Go (PAYG) Health Care Insurance}

Clearly an important determinant of the high levels of spending on terminal care is due to public subsidization of demand, in the United States mostly through Medicare and Medicaid. To consider the determinants of the size of public subsidies, consider the public pay-as-you-go (PAYG) insurance that finances most health care spending in the developed world. This is a natural extension of the analysis under altruism with children, except that now each parent is being subsidized by the average child in the economy as opposed to their own child in the previous section.

The classic effects of any demand subsidies are of course to raise the supply-price, lower the demand-price, and raise quantity. Consequently, terminal care spending, the product of the supply-price and the quantity, will be positively affected by demand subsidies. Demand subsidies for health care in many countries, including Medicare and Medicaid in the US, differ from classic demand subsidies in that they also involve third-party (administrative) pricing. Nevertheless, and particularly for the poor, the demand subsidy aspect through third-party financing is clearly an important factor in determining the high level of terminal care spending.

However, we here argue that there exists evidence that suggest that even in absence of demand subsidies, the level of terminal care spending would be higher than accounted for by existing value of life estimates. Indeed, there is a large literature in health economics, the most prominent study being the RAND Health Insurance Experiment ${ }^{7}$, that has attempted to estimate the effect of co-pays on health care spending. Interpreting co-pays as unsubsidized care, this literature has implications for the counterfactual spending that would take place in absence of demand subsidies ${ }^{8}$. In particular, consider the benchmark RAND experiment estimate under which spending under full co-pays is about $70 \%$ of

\footnotetext{
${ }^{7}$ Other more recent studies on the effect of public demand subsidies include Card, et al (2004), Finkelstein et al (2005).

${ }^{8}$ Indeed, The RAND Health Insurance Experiment was ideally suited to study public subsidization as premiums were never collected by participants, mimicking the effects of differentially generous taxfinanced plans. The experiment therefore had less implications for private demand of care as it also involves an elastic ex-ante demand for insurance itself, rather than the studied demand for care ex-post.
} 
spending under no co-pays or fully subsidized care. In this benchmark case then, terminal care spending would be about $70 \%$ of observed levels. But even when discounting spending due to subsidies in this manner, it appears that terminal care spending is higher than common estimates of the value of a life. Even if we assume that for every 100 thousand dollars spent on public terminal care, 70 thousand would be spent without public subsidies, spending levels on terminal care are many times still very high relative to existing value of life estimates. Therefore, this suggests that using standard co-pay estimates to predict unsubsidized demand may not alter our basic argument. This is particularly true, if as often found, acute hospital inpatient care is less elastic to co-pays than is other forms of care.

The overall analysis of PAYG insured terminal care is analogous to multiple children and parents who exhibit heterogeneous altruism towards each others, where presumably within-family altruism is stronger than across-family altruism. Therefore, such altruistic and PAYG financed terminal care have many analogous features to the analysis of a single family before. Again, it is the relative altruism of the old relative to the young that matters for whether a PAYG financed health care program has a larger value of saving an adult from dying compared to the adult himself. If younger generations cannot tolerate old people dying without state of the art terminal care more than the older generations care about public deficits, then optimal spending levels may be well beyond the average wealth of the dying generation.

\section{Section 5: The Quality of a Life Year and the Value of Extending It}

It is often argued that life-extension should be allocated towards individuals in good health rather than poor health. In this section we analyze rational terminal care as a function of the level of health or "quality" of life. We stress that terminal care often is larger for frail patients than commonly argued. Even though a person may be frail and in very ill health, it may nevertheless be rational for him to value life-extension as much as a perfectly healthy person. A special case of this is the analysis above where the opportunity cost of wealth is zero for a dying self-interested individual, regardless of whether that individual is frail or healthy.

\section{Valuation of a Quality Dependent Life}

More precisely, consider when the annual utility function $U(c, q)$ is extended to depend positively on both consumption $c$ and quality of life $q$. For a given quality of life, consider the indirect utility when full consumption smoothing takes place over time

$$
V(Y, S)=A U(Y / A, q)
$$

The infra-marginal value of life $v(q)$ for a given level of quality $q$ is then defined by

$$
A^{\prime} U\left(Y / A^{\prime}-v(q), q\right)=A U(Y / A, q)
$$


This has the direct implication that the quality of life has two offsetting effects on the value of life. First, quality raises the value of life by raising the level of utility under the improved survival (left-hand side) because living longer is enjoyed more when the quality of that life is higher. However, note that as a second effect it also raises the value of the remaining life at the lower survival (right-hand side). Therefore, a higher quality of life means the new life is enjoyed more but also means the old life is as well. The second effect is due to that the cost of foregone consumption used to finance life extension rises with quality. Dependent on the complementarity between consumption and the quality of life, the cross partial of $U$, the value of life $v(q)$ may be falling or rising in the quality of life. In can be shown that for particular utility functions, the two effects will be fully offsetting making the value of life independent of the quality of life; $d v(q) / d q=0$.

Note that this result does not imply that holding constant quantity of life a rise in quality is not valued. It is still true that an increase in $q$ is valuable holding constant the survival $S$. Rather, the two offsetting effects above are about the interaction and states that the value of prolonging life may not depend on the level of quality; the value of changing $S$ for different levels of $q$.

\section{Section 6: Insurance for Terminal Care}

The previous analysis considered the ex-post allocation problem of terminal care conditional upon a disease occurring. We here consider the ex-ante allocation problem of deciding how much wealth to allocate towards a potential future disease occurrence involving expensive terminal care. This will determine the willingness to pay for an insurance policy that covered terminal care were it to be necessary in the future.

Let $f$ be the probability of a terminal illness occurring in which case the person faces death unless treated. Assume for ease of exposition that no care is purchased if the person is uninsured and that if he is insured he is treated and his survival prospects are $S$ ' as before. The individual does not contract the disease with probability (1-f) in which case he faces the normal survival $S$. The willingness to pay for such coverage, $v$, is now determined by how much wealth the individual is willing to give up ex-ante in order to obtain the survival S' if the terminal illness would occur in the future. This willingness to pay for terminal care insurance is determined by

$$
f V\left(Y-v, S^{\prime}\right)+(1-f) V(Y-v, S)=f V(Y, 0)+(1-f) V(Y, S)
$$

If the individual was to give up all his wealth today for terminal care when needed in the future, the left-hand side would be zero and the right-hand side positive. Therefore, as opposed to the case for the ex-post willingness to pay for terminal care, the ex-ante willingness to pay is not equal to the individuals' level of wealth; $v<Y$. This is of course because the individual trades off other uses of the wealth when making the ex-ante decision, in particular consuming the wealth if the individual does not become terminally ill. 
The effects of the parameters facing the individual on the willingness to pay for terminal care insurance are illustrated in Figure 1 below. It depicts three indirect utility functions as a function of income; one for each of the survivals $V(Y, S)>V\left(Y, S^{\prime}\right)>V(Y, 0)$.

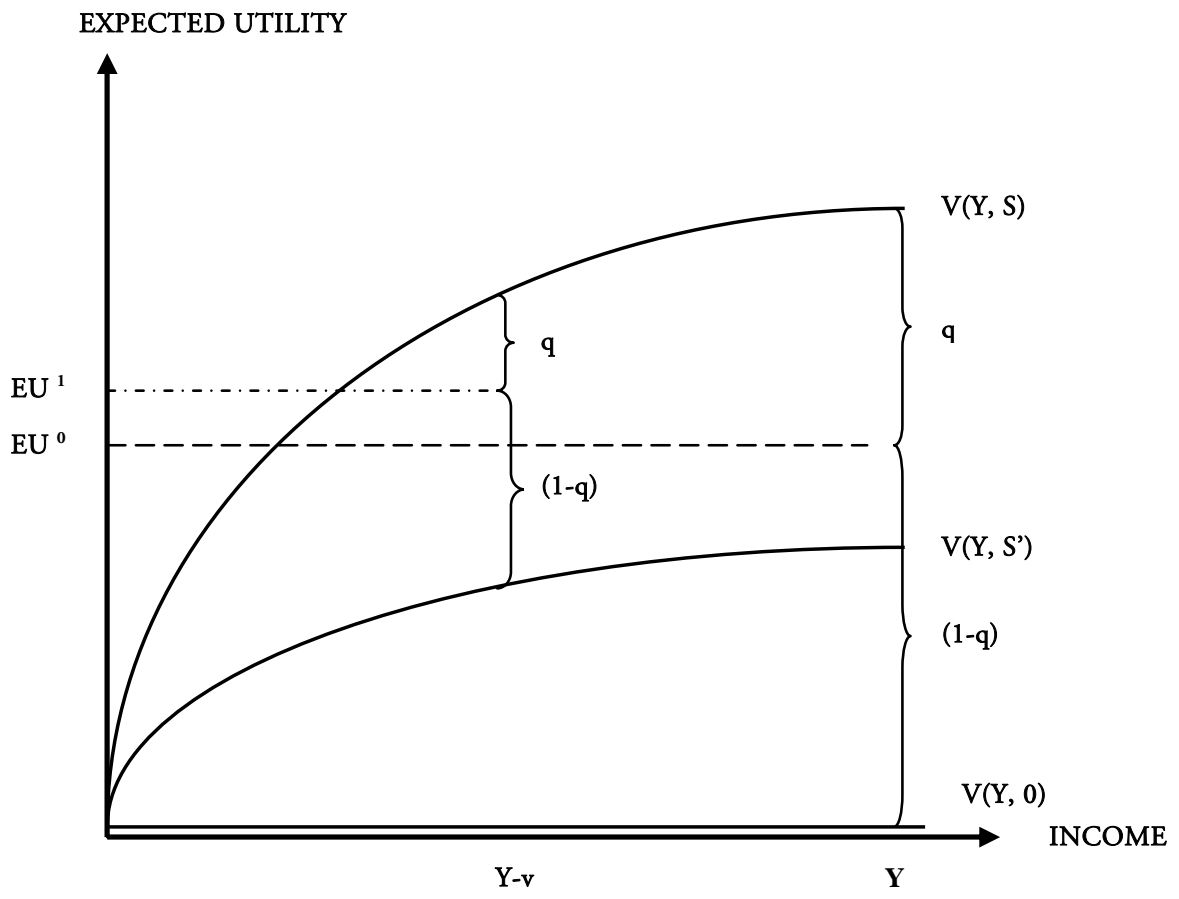

FIGURE 1: TERMINAL CARE INSURANCE

If the individual goes uninsured then he is faced with the expected utility $E U^{0}$ indicated in the figure, which is a f-weighted average of $V(Y, S)$ and $V(Y, 0)$. If he pays $v$ for the insurance he is faced with the expected utility $E U^{l}$ in the figure, which is a f-weighted average of $V(Y-v, S)$ and $V\left(Y-v, S^{\prime}\right)$. Consequently, the maximum amount $v$ that the individual is willing to pay is the amount that brings down expected utility of being insured $E U^{l}$ to the level of expected utility of being uninsured $E U^{0}$ in the figure.

The figure illustrates directly that the willingness to pay ex-ante for terminal care is only equal to wealth in case of the illness occurring with certainty making up the special case of the previous analysis. More generally, the figure reveals that the willingness to pay for the insurance rises with the probability of terminal illness; $v$ rises with $f$. In addition, naturally, the individual is not wiling to pay anything unless there is a chance of the illness occurring, so that $f=0$ implies $v=0$, and is willing to pay his entire wealth when it occurs for sure, so that $f=1$ implies $v=Y$. Naturally, terminal care insurance is more valuable for common terminal illnesses, e.g. cancers, than for rare ones.

The figure also illustrates the straightforward implication that the willingness to pay for terminal care insurance rises with the survival enabled by the terminal care, that is, $v$ rises with the survival $S^{\prime}$. This is because a rise in the survival $S^{\prime}$ that takes place in presence of care raises the expected utility of being insured $E U^{l}$ but does not affect the expected utility of being uninsured $E U^{0}$. Consequently, the willingness to pay to be insured rises. 
Lastly, the figure illustrates that the survival of the person absence the occurrence of terminal illness, $S$, has an indeterminate effect on the willingness to pay for terminal care insurance. This is because better health in absence of the illness occurring raises both the expected utility of being uninsured and insured. Dependent on the shape of the indirect utility function, the willingness to pay for terminal care insurance rises or falls with $S$. This is analogous to the indeterminacy of the quality of life affecting the ex-post valuation of life and terminal care discussed earlier.

\section{Section 7: Research and Development of Terminal Care Technologies}

Our analysis stresses the high value of terminal care given the existence of technologies to extend life when it is threatened. This section considers the incentives for bringing such technologies to exist in the first place through medical R\&D. The major issue we discuss is how the presence of altruism affects optimal R\&D. The presence of altruism in affecting the efficient amount of technological change is poorly understood by economists ${ }^{9}$, but seems central to understanding whether health care spending is growing at the appropriate rate.

We previously discussed the difference between the social and private value of life given the existence of a technology. There is an important aspect of terminal care, indeed for health care in life-threatening conditions in general, which concerns the desire to avoid denying treatments to dying patients. Indeed, many times doctors express concerns that it is "unethical" to deny any patient the use of existing technology in life-threatening situations and this has led to sharp disagreements between doctors and economists on appropriate care. Terminal care is perhaps the starkest case where this issue arises. We here stress that such preferences have important implications for the appropriate technological change over time, and hence for the appropriate change in health care spending over time. The issue we focus on is when there is an aversion to denying existing technologies to care for dying patients, which seems central to the issue of terminal care.

Consider when this takes the form that an altruist prefers someone not receiving care in the absence of a technology to denying care in the presence of a technology. Such interactions of the demand for altruistic care with new goods have important and unrecognized effects for the optimal degree of technological change, and hence for the optimal growth in health care spending. It is often true that when a new good appears in the utility function, here a new technology being consumed by the patients and altruists, it affects demand for other goods, as e.g. analyzed for the case of advertising by Becker and Murphy (1994). In particular, let $W^{1}$ be the social surplus when using the developed terminal care technology and $W^{0}$ when not using the developed technology. Now let $N$ denote the social surplus when the technology is not developed at all and thus cannot be used. We assume that there is a social surplus from using the technology if it gets

\footnotetext{
${ }^{9}$ See Philipson, Mechoulan, and Jena (2006) for an analysis of this issue.
} 
developed so that $W^{1}>W^{0}$. This surplus may come from patients themselves or from altruistic payers of that care. In a standard analysis, it would be the case that not using a developed technology or not having it developed would entail the same ex-post surplus; $W^{0}=N$. The terminally ill patient would be indifferent because he obtained the same health and the altruists would be indifferent because their wealth would be unchanged and the health and wealth of the patient would be as well. However, if it is the case that the willingness to pay for care by altruists interacts with the presence of a new technology then this equality may not hold. In particular, if altruists prefer no technology to not using it when available then $N>W^{0}$.

In this case, the surplus conditional on developing the technology does not correspond in a standard manner to the value of $R \& D$ investments to generate the technology in the first place. In particular, let $P(R)$ be the probability of discovery of the technology given $\mathrm{R} \& \mathrm{D}$ investment $R$. The expected surplus of developing the technology is then

$$
\max _{R} P(R) W^{1}+(1-P(R)) N-R
$$

This has the necessary first-order condition for an interior solution

$$
P_{R}\left(W^{1}-N\right)=1
$$

As this makes clear, the marginal benefit on the left-hand side, the difference $W^{1}-N$ drives efficient R\&D. However, the difference $W^{1}-W^{0}$ is usually how the ex-post value of a new technology is assessed, by assuming that the pre-innovation surplus $W^{0}$ is the welfare for which the price is sufficiently high to make the demand for the innovation vanish (for an empirical example, see e.g. Hausman (2000)). However, the difference, $N-W^{0}$, which can be taken as a measure of the aversion to denying care, determines how efficient $R \& D$ diverts from traditionally discussed efficient levels of $R \& D$. In the standard extreme case when there is no denial aversion, $N=W^{0}$, then the ex-post surplus guides optimal R\&D investment in a standard manner. At the other extreme is when denial aversion is so large that optimal use of the technology when developed is dominated by no use of an undeveloped technology; $N>W^{1}>W^{0}$. In that case, even though the technology is demanded ex-post and generates a surplus larger than $R \& D$ costs, there should be no R\&D. In health economic jargon, a technology may well be cost effective in that measured health benefits are lower than costs, but nevertheless should not have been developed. In the intermediary case, denial version lowers the value of $R \& D$ and provides a wedge between the size of the generated surplus ex-post and the optimal amount of R\&D. Put simply; extensive and valuable ex-post usage of expensive terminal care technologies does not necessarily warrant more R\&D to develop them.

Note that under denial aversion many of the canonical aspects of the classic economics of innovation do not apply. This is because the interaction between the willingness to pay for care from the introduction of the new good. First, ex-post social surplus does not determine the optimal amount of R\&D ex-ante. A technology can generate a social 
surplus ex-post even though it should never have been developed in the first place. Second, welfare analysis of new innovations usually assume that they are pricereductions from a pre-innovation price that makes demand vanish. However, denial aversion implies that an innovation is not merely a price reduction but also represents a shift in the social demand curve, a shift which may well be consistent with a meta-utility function covering both undiscovered and discovered goods..

Indeed, this aspect of technological change has important implications for the worldwide incidence of R\&D. It is well known that US is about above 60 percent of world sales for pharmaceuticals, as opposed to average industry in which it is considerably lower as about 23 percent of worlds income is generated in the US. This fact is often used to argue that US markets drive drug R\&D spending in US or elsewhere and that the positive external effects from US R\&D are not paid for by foreign countries. However, under denial aversion countries outside of the US may well be hurt by such technological change, if they are better of not providing care in absence of a technology than they are denying care in its presence. In other words, there may be negative, as opposed to positive external effects of US driven technological change.

\section{Section 8: Concluding Remarks}

Despite the skepticism the high spending on medical care at the end of life often encounters from payers and policy makers, it may be rational. We analyzed the incentives giving rise to larger spending levels on terminal care than the existing value of life estimates in the empirical literature. We stressed the low opportunity cost of spending near death, the importance of hope, the greater social value of a life, as well as the insignificance in quality of life in lowering its value. We showed how an ex-ante perspective in terms of insurance and $R \& D$ altered some of these conclusions. Our analysis differed from previous analysis by attempting to systematically understand the high, indeed often extreme, spending levels we observe for terminal care and explaining why such spending levels are often order of magnitudes higher than existing empirical estimates of the value of a life.

\section{Future Empirical Analysis}

Our claim that the value of life may be higher near its end than traditionally thought needs more careful empirical examination in future research. There exist some existing estimates that suggest that the value of life near its end may be relatively high. Peter Neumann and colleagues (2006) have found that new oncology treatments at the end of life are valued at about $\$ 300$ thousand per life year, nearly three times the most commonly cited values of a life year of $\$ 100$ thousand. Moreover, the rapid uptake of new and expensive end-of-life treatments by patients suggests that they are highly valued. Goldman et al (2007) provides evidence on the elasticity of the demand for specialty drugs as a function of the co-pays of patients. They find that the demand for specialty drugs and end of life biologics is less elastic to co-pays than other drugs, partly 
explaining their relatively high prices as well as suggesting a high degree of gross consumer surplus consistent with a low elasticity of demand. The willingness to pay for expensive terminal care should be estimated using such demand curves, as many times the consumer surplus, rather than the spending, is missed in traditional analysis of medical products. In particular, using demand curves would differ from so called "costeffectiveness analysis" which compares the spending on care with the health benefits induced. Demand analysis would estimate the gross consumer surplus, that is, consumer surplus and spending, as opposed to measuring the cost per life-year which would only take into account the spending involved. More precisely, if the price of a drug was $\mathrm{P}$ that raised longevity by $\mathrm{T}$ years, then the cost per life-year would be $\mathrm{P} / \mathrm{T}$. However, this ignores the consumer surplus involved, that is, the gains to consumers of increased longevity beyond the price $\mathrm{P}$ they pay. In general, the demand for recent biologics and other expensive terminal care treatments bears directly on our prediction of a larger valuation of terminal care than the existing marginal estimates of the value of life implies. Note that the value of life revealed by co-pay demand curves is on top of any public payment for the care, which if it reflects altruism, will greatly enhance the social value of a life even further. We suspect that it may well be the case that such an estimation of the value of life near its end are orders of magnitude higher than the marginal estimates of the value of a life year commonly estimated in other settings.

\section{Future Normative Analysis}

Although our aim was mainly positive, our analysis has important normative implications as well. In particular, it has strong implications for using so called cost-effectiveness, cost-utility, or cost-benefit criteria in adopting medical technology in private and public health plans ${ }^{10}$. CE analysis has been the major method proposed to evaluate new medical inventions and has been argued to be central in managing new technologies, their adoptions, and their impact on health care spending. Examples include cost-effectiveness using spending per quality- or disability adjusted life years, as is used by some public buyers as in the UK, or cost-benefit analysis monetizing mortality reductions through value-of-life estimates, as is common in studies assessing the gains of increased health care spending. In general, our analysis stressed the incentives that implied larger valuations than simply multiplying out the average treatment effect on survival from a technology by estimates of the value of a life year from existing studies using private and marginal valuations. Such a valuation scheme is essentially a linear valuation method, which contrasts with our claim that there are important non-linearities in the valuation of life.

In addition, for purposes of insurance coverage, it is important to learn more about the elasticity of demand for terminal care in as much as it induces optimal benefit design. Moral hazard in the context of health care has focused on the tradeoff between incentives

\footnotetext{
10 The literature is vast, but for examples, see Weinstein and Stason (1977), Johanneson and Weinstein (1993), Gold et al. (1996), Meltzer (1997), Drummond et al. (1997), Garber and Phelps (1997), Garber (2000), and Cutler (2005).
} 
and risk in the use of medical services. On the one extreme, full insurance leads to overconsumption ex-post, because prices are below cost of production. On the other extreme, having the right incentives ex-post through cost-based pricing implies there is too much risk-bearing. Thus, as the argument goes, there is a tradeoff between risk-sharing and appropriate incentives in providing insurance that effects medical care use (Mark V, Pauly 1968; Richard Zeckhauser 1970;). A major implication of the standard theory is that co-pays should fall the more inelastic demand is for the medical services, since the cost of over-consumption falls the less elastic demand is. The RAND Health Insurance Experiment (HIE) found that elasticities for various types of health care services differ-inpatient and outpatient care was the least elastic, whereas use of dental and mental health services were most responsive to changes in co-payments (Joseph P. Newhouse, 1993). This finding partially explains why virtually every health insurer covers hospital and ambulatory care, but not necessarily these other services. Even when such services are covered, they often have much greater cost-sharing. This logic implies that if the estimates suggesting an inelastic demand for specialty drugs or biologics generalize to other forms of terminal care, terminal care should highly insured. The common argument that insured terminal care is wasted on people going to their grave may ignore that the demand for this type of care is very inelastic and hence should be insured. 


\section{References}

Becker, G.S. and K.M. Murphy. (1993). “A Simple Theory of Advertising as a Good.” The Quarterly Journal of Economics, v108 (4); 941-964.

Becker, G.S., T. Philipson and R.R. Soares. (2003). "The Quantity and Quality of Life and the Evolution of World Inequality.” American Economic Review, v95; 277291.

Card, D.E., C. Dobkin and N. Maestas. (2004). "The Impact of Nearly Universal Insurance Coverage on Health Care Utilization and Health: Evidence from Medicare" Mar., NBER Working Paper No. W10365. Available at SSRN: http://ssrn.com/abstract $=516706$

Cutler, D.M. (2004). Your Money or Your Life: Strong Medicine for America's Health Care System. Oxford University Press, New York, NY.

Dow, W.H., T. Philipson, X. Sala-i-Martin. (1999). "Longevity Complementarities under Competing Risks.” The American Economic Review, v89 (5) Dec.; 1358-1371. http://links.jstor.org/sici?sici=00028282\%28199912\%2989\%3A5\%3C1358\%3ALCUCR\%3E2.0.CO\%3B2-7

Drummond, M.F., B. O’Brien, G.L. Stoddart, and G.W. Torrance. (1997). Methods for the Economic Evaluation of Health Care Programmes. Oxford University Press.

Finkelstein, A. and R. McKnight. (2005). "What Did Medicare Do (and Was It Worth It)?" Sept., NBER Working Paper No. W11609 Available at SSRN: http://ssrn.com/abstract $=804255$

Garber, A.M. and C.E. Phelps. (1997). "Economic Foundations of Cost-Effectiveness Analysis," Journal of Health Economics, v16; 1-32.

Garber, A.M. (1999). “Advances in Cost-Effectiveness Analysis of Health Interventions,” NBER Working Paper No. 7198.

Gold, M.R., J.E. Siegel, L.B. Russell and M.C. Weinstein. (1996). Cost-Effectiveness in Health and Medicine. Oxford University Press.

Goldman, D., G. Joyce, G. Lawless, W. Crown, and V. Willey. (2007). "Benefit Design and Specialty Drug Use”, Health Affairs, v25 (5); 1319-1331.

Hausman, J. (2000). "Efficiency Effects On The U.S. Economy From Wireless Taxation," National Tax Journal, v53 (Part 2); 733-942.

Himmelstein D., E. Warren, D. Thorne, and S. Woolhandler. (2005). "Illness and Injury as Contributors to Bankruptcy", Health Affairs, Feb. 2. Web exclusive 
10.1377/hlthaff.w5.63.

http://content.healthaffairs.org/cgi/content/full/hlthaff.w5.63/DC1

Hirth, R.A., M.E. Chernew, E. Miller, A.M. Fendrick, and W.G. Weissert. (2000). "Willingness to Pay for a Quality Adjusted Life Year: In Search of a Standard." Medical decision Making, v20; 332-342.

Hogan, C., J. Lunney, J. Gabel, and J. Lynn. (2001). "Medicare Beneficiaries Cost of Care in the Last Year of Life," Health Affairs, v4 (20); 188-195.

Johannesson, M., and M.C. Weinstein. (1993). "On the Decision Rules of CostEffectiveness Analysis,” Journal of Health Economics, v12; 459-467.

Lubitz, J.D. and G.F. Riley. (1993). "Trends in Medicare Payments in the Last Year of Life.” New England Journal of Medicine, v328 (15); 1092-1096.

Meltzer, D. (1997). "Accounting for Future Costs in Medical Cost-Effectiveness Analysis," Journal of Health Economics, v16; 33-64.

Murphy, M. and R. Topel. (2003). "The Economic Value of Medical Research.” in Measuring the Gains from Medical Research: An Economic Approach, (Murphy and Topel, eds). University Of Chicago Press; 41-73.

Nadler, E., B. Eckert and P.J. Neumann. (2006). "Do Oncologists Believe New Cancer Drugs Offer Good Value?" The Oncologist, v11 (2); 90-95.

Phelps, C.E., and S.T. Parente. (1990). "Priority Setting in Medical Technology and Medical Practice Assessment," Medical Care, v28; 703-723.

Philipson, T. and G.S. Becker. (1996). "Old-Age Longevity and Mortality-Contingent Claims." Journal of Political Economy, v106; 551-573.

Philipson, T. and A.B. Jena. (2006). "Surplus Appropriation from R\&D and Health Care Technology Assessment Procedures,” NBER Working Paper No. 12016.

Philipson, T., S. Mechoulan, and A.B. Jena. (2006). "I.P. and External Consumption Effects: Generalizations from Health Care Market.” NBER Working Paper No. W11930.

Raisel, E., K. Weinfurt, and K. Schulman. (2005). "Can Prospect Theory Explain RiskSeeking Behavior by Terminally Ill Patients”, Medical Decision Making, v25; 609-613.

Weinstein, M.C., and W.G. Manning. (1997). "Theoretical Issues in CostEffectiveness Analysis" Journal of Health Economics, v16; 121-128. 
Weinstein, M.C., and W.B. Stason. (1977). "Foundations of Cost-Effectiveness Analysis for Health and Medical Practices.” New England Journal of Medicine, v296; 716721. 